\title{
PENGARUH PERILAKU KEPEMIMPINAN KEPALA SEKOLAH DAN BUDAYA ORGANISASI TERHADAP MOTIVASI KERJA GURU SD NEGERI PADA GUGUS DEWI SARTIKA DI UPTD PENDIDIKAN KECAMATAN SUKRA KABUPATEN INDRAMAYU
}

\author{
Sujono \\ SD Negeri Sukra 1, Desa Sukra Bobor, Sukra, Indramayu - Jawa Barat, sujono2019@gmail.com
}

\begin{abstract}
ABSTRAK
Fokus penelitian ini adalah untuk mengetahui dan menganalisis besaran pengaruh perilaku kepemimpinan kepala sekolah dan budaya organisasi terhadap motivasi kerja guru SD Negeri pada Gugus Dewi Sartika di UPTD Pendidikan Kecamatan Sukra Kabupaten Indramayu baik secara parsial maupun ganda. Metode dalam penelitian ini menggunakan pendekatan kuantitatif dalam menjaring data. Hasil penelitian menunjukkan bahwa: (1) Terdapat pengaruh yang signifikan antara perilaku kepemimpinan kepala sekolah terhadap motivasi kerja guru (2) Terdapat pengaruh yang signifikan antara budaya organisasi terhadap motivasi kerja (3) Terdapat pengaruh yang signifikan antara perilaku kepemimpinan kepala sekolah dan budaya organisasi secara bersama-sama terhadap motivasi kerja guru. Bertolak dari hasil penelitian tersebut, disarankan bahwa: (1) Hal-hal yang harus dilakukan oleh kepala sekolah dalam upaya untuk memotivasi guru adalah dengan lebih meningkatkan keterlibatan para guru dalam proses perumusan aktivitas kerja. Dimana dengan meningkatkan keterlibatan guru tersebut selain munculnya ide dan saran yang akan memperlancar proses aktivitas kerja, diharapkan pula para guru akan lebih bertanggung jawab dalam pelaksanaan tugas yang diembannya. (2) Baik guru maupun kepala sekolah diupayakan selalu menjaga tatanan nilai, kebiasaan-kebiasaan, dan kesepakatan-kesepakatan yang direfleksikan dalam tingkah laku keseharian dengan menumbuhkan kepercayaan, kekhasan, dan pola perilaku agar terbangun budaya organisasi yang kondusif sehingga menumbuhkembangkan motivasi kerja guru. (3) Guna memelihara motivasi kerja guru hendaknya dapat lebih menjaga kelancaran alur komunikasi, mempererat hubungan antar guru, serta bersikap lebih adil dan terbuka dalam penanganan konflik yang sedang terjadi.
\end{abstract}

Kata Kunci: Perilaku Kepemimpinan, Budaya Organisasi dan Motivasi Kerja

\begin{abstract}
The focus of this research is to find out and analyze the magnitude of the influence of school principals' leadership behavior and organizational culture on the work motivation of elementary school teachers in the Dewi Sartika cluster in the UPTD Education District of Sukra, Indramayu Regency, both partially and double. The method in this study uses a quantitative approach in capturing data. The results showed that: (1) There was a significant influence between the leadership behavior of principals on teacher work motivation (2) There was a significant influence between organizational culture on work motivation (3) There was a significant effect between the leadership behavior of principals and organizational culture as a together towards the teacher's work motivation. Starting from the results of the study, it is suggested that: (1) The things that must be done by the principal in an effort to motivate teachers is to further increase the involvement of teachers in the process of formulating work activities. Where by increasing the involvement of these teachers in addition to the emergence of ideas and suggestions that will expedite the process of work activities, it is also expected that teachers will be more responsible in carrying out the tasks they carry. (2) Both teachers and principals are strived to always maintain the order of values, habits, and agreements that are reflected in daily behavior by fostering trust, uniqueness, and behavior patterns in order to build a conducive organizational culture so as to foster motivation for guuru work motivation. (3) In order to maintain the work motivation of teachers, they should be able to better maintain the smooth flow of communication, strengthen relationships between teachers, and be more fair and open in handling conflicts that are happening.
\end{abstract}

Keywords: Leadership Behavior, Organizational Culture and Work Motivation 


\section{PENDAHULUAN}

Sebagaimana dikemukakan Wursanto yaitu bahwa motivasi berhubungan dengan faktor psikologis seseorang yang mencerminkan hubungan antara sikap, kebutuhan, dan kepuasan yang terjadi pada diri manusia. (Wursanto, 2000)

Menurut teori Herzberg, bahwa kepuasan pekerjaan ini selalu dihubungkan dengan isi dan jenis pekerjaan yang disebut motivator yang meliputi yang meliputi penghargaan aktualisasi diri. (Azis, 2007)

Kepemimpinan kepala sekolah pada hakikat nya menurut Sutisna adalah proses mempengaruhi seorang atau kelompok dalam usaha-usaha pencapaian tujuan. (Sutisna, 2005)

Diakui oleh Robbins bahwa para teoritisi organisasi dewasa ini telah mengakui dan menyadari pentingnya peran yang dimainkan budaya dalam kehidupan organisasi (Robbins, S.P, 2002)

Mengacu pada Undang-undang Republik Indonesia Nomor 20 Tahun 2003 Tentang Sistem Pendidikan Nasional, bab I pasal 1 sampai dengan pasal 3 sebagai berikut :

1) Pendidikan adalah usaha sadar dan terencana untuk mewujudkan suasana belajar dan proses pembelajaran agar peserta didik secara aktif mengembangkan potensi dirinya untuk memiliki kekuatan spiritual keagamaan, pengendalian diri, kepribadian, kecerdasan, akhlak mulia, serta keterampilan yang diperlukan dirinya, masyarakat, bangsa dan negara. 2) Pendidikan nasional adalah pendidikan yang berdasarkan Pancasila dan UndangUndang Dasar Negara Republik Indonesia Tahun 1945 yang berakar pada nilai-nilai agama, kebudayaan nasional Indonesia dan tanggap terhadap tuntutan perubahan zaman. 3) Sistem pendidikan nasional adalah keseluruhan komponen pendidikan yang saling terkait secara terpadu untuk mencapai tujuan pendidikan nasional.

Gibson secara lebih khusus mengatakan "Kepemimpinan adalah suatu usaha mempengaruhi orang antar perseorangan (interpersonal)", lewat proses komunikasi untuk mecapai sesuatu atau beberapa tujuan. (Gibson, 2005)

Hakekat pemimpin adalah seorang yang mempunyai kemampuan untuk mempengaruhi perilaku orang lain di dalam kerjanya dengan menggunakan kekuasaan. Kekuasaan adalah kemampuan untuk mengarahkan dan memepengaruhi bawahan sehubungan dengan tugas-tugas yang harus dilaksanakannnya. Menurut Stoner semakin banyak sumber kekuasaan yang 
tersedia bagi pimpinan, akan makin besar potensi kepemimpinan yang efektif. (Fattah, 2006)

Danim mendefinisikan kepemimpinan sebagai berikut: "Kepemimpinan adalah setiap perbuatan yang dilakuakan oleh individu atau kelompok untuk mengorganisasikan dan member arah kepada individu atau kelompok yang tergabung disalam wadah tertentu untuk mencapai tujuan yang telah ditetapkan sebelumnya.”(Danim, 2007)

Sedangkan MC Farland mengemukan bahwa kepemimpinan adalah suatu proses dimana pimpinan dilukiskan akan member pemerintah atau pengaruh, bimbingan atau mempengaruhi pekerjaan orang lain dalam memilih dan mencapai tujuan yang telah ditetapkan. (Danim, 2007)

Pfifiner mengemukan bahwa kepemimpinan adalah mengordinasikan dan memberi arah kepada individu atau kelompok untuk mencapai tujuan yang diinginkan. (Danim, 2007). Lipham menyatakan kepemimpinan ditekankan pada inovasi dan perubahan dari para pemimpin dipandang menjadi dipandu oleh perasaan yang baik untuk sebuah organisasi dan oleh sebuah perhatian untuk berbagai konsekuensi yang lebih penting dari pada hanya sekadar peraturan, prosedur, dan regulasi. (Razik, 2005).

Rivai menyatakan bahwa dinamika kepemimpinan dalam praktiknya dipengaruhi oleh tiga faktor yaitu: hubungan manusiawi dalam kepemimpinan, proses pengambilan keputusan, dan pengendalian dalam kepemimpinan. (Rivai, 2005). Thoha menyatakan bahwa dalam hubungannya dengan perilaku pemimpin ini ada dua dimensi, yakni: perilaku mengarahkan dan perilaku mendukung yang merupakan gaya dasar kepemimpinan. Dimensi yang berkenaan dengan tingkat kemampuan mengarahkan (direction) dalam tindakan atau aktivitas pemimpin. Dimensi yang berkenaan dengan tingkat dukungan (support) atau keterlibatan orang-orang yang dipimpin dalam melaksanakan tugas-tugas pokok kelompok atau organisasi. (Thoha, 2005)

Gibson menjabarkan empat perilaku kepemimpinan tersebut berupa: (1)Perilaku yang timbul karena sesuatu sebab, (2) Perilaku diarahkan kepada tujuan. (3) Perilaku yang terarah kepada tujuan dapat diganggu oleh prestasi, konflik, dan kegelisahan. (4) Perilaku timbul karena motivasi. (Gibson, 2005)

Robbins mengemukakan bahwa budaya organisasi merupakan sistem makna bersama yang dianut oleh anggota- 
anggota yang membedakan organisasi itu dari organisasi-organisasi lain. (Robbins, 2002)

Pendapat ini sejalan dengan batasan budaya organisasi yang dikemukakan oleh Mondy, dkk yang menyatakan bahwa budaya organisasi merupakan "The system of shared values, beliefs, and habbits within an organization that interacts with the formal structure to produce behaviour norms." (Suatu sistem berbagi atas nilai, keyakinan, dan kebiasaan di dalam suatu organisasi yang sesuai dengan struktur formal untuk menghasilkan norma-norma perilaku). (Mondy, dkk., 2005)

Fred Luthans mendefinisikan budaya organisasi sebagai pola asumsi yang ditemukan dan dikembangkan oleh kelompok yang mencakup masalah adaptasi dengan pihak luar dan integrasi yang telah berjalan dengan cukup baik dan reliabel untuk diajarkan kepada para anggota baru sebagai tata cara berperilaku, berfikir dan bersikap terhadap permasalahan itu. (Luthans, 2006)

Edgar Scheim mendefinisikan budaya sebagai:

A pattern of shared basic assumptions that the group learned as it solved its problems of external adaptation and internal integration, that has worked well enough to be considered valid and, therefore, to be taught to new members as the correct way you perceive, think, and feel in relation to those problems. Pendapat ini mengatakan bahwa budaya organisasi merupakan suatu pola berbagi atas asumsi-asumsi dasar yang dikembangkan oleh kelompok pada saat mengadaptasi pengaruh dari luar dan mengintegrasikannya ke dalam kelompok. Di mana asumsi-asumsi dasar tersebut telah berfungsi dengan cukup baik dan dianggap valid. Sehingga asumsi-asumsi dasar tersebut dapat diajarkan kepada anggota baru sebagai cara yang benar untuk menerima, memikirkan, dan merasakan untuk penyelesaian masalah kelompok. Kata kunci dari pengertian budaya yaitu berbagi asumsi-asumsi dasar (shared basic assumptions) yang meliputi keyakinan dan nilai-nilai. (Scheim, 2005) Scheim mengemukakan sepuluh karakteristik budaya organisasi, mencakup: (1) observe behavior: language, customs, traditions; (2) groups norms: standards and values; (3) exposed values: published, publicly announced values; (4) formal philosophy: mission; (5) rules of the game: rules to all in organization; (6) climate: climate of group in interaction; (7) embedded skills; (8) habits of thinking, acting, paradigms: 
shared knowledge for socialization; (9) shared meanings of the group; dan (10) metaphors or symbols. (Scheim, 2005)

Luthan mengetengahkan enam karakteristik penting dari budaya organisasi, yaitu: (1) obeserved behavioral regularities; yakni keberaturan cara bertindak dari para anggota yang tampak teramati. Ketika anggota organisasi berinteraksi dengan anggota lainnya, mereka mungkin menggunakan bahasa umum, istilah, atau ritual tertentu; (2) norms; yakni berbagai standar perilaku yang ada, termasuk di dalamnya tentang pedoman sejauh mana suatu pekerjaan harus dilakukan; (3) dominant values; yaitu adanya nilai-nilai inti yang dianut bersama oleh seluruh anggota organisasi, misalnya tentang kualitas produk yang tinggi, absensi yang rendah atau efisiensi yang tinggi; (4) philosophy; yakni adanya kebijakan-kebijakan yang berkenaan dengan keyakinan organisasi dalam memperlakukan pelanggan dan karyawan; (5) rules; yaitu adanya pedoman yang ketat, dikaitkan dengan kemajuan organisasi (6) organization cilmate; merupakan perasaan keseluruhan (an overall "feeling") yang tergambarkan dan disampaikan melalui kondisi tata ruang, cara berinteraksi para anggota organisasi dan cara anggota organisasi memperlakukan dirinya, pelanggan atau orang lain. (Luthans, 2006)

Robbins menyebutkan ada tujuh karakteristik primer yang merupakan hakikat dari budaya organisasi, yaitu: (1) Inovasi dan pengambilan resiko: sejauh mana para karyawan didorong agar inovatif dan mengambil resiko. (2) Perhatian terhadap detail. Sejauh mana para karyawan diharapkan memperilhatkan presisi (kecermatan), analisis, dan perhatian terhadap detail. (3) Orientasi hasil: Sejauh mana manajemen memusatkan perhatian pada hasil dan bukannya pada teknik dan proses yang digunakan untuk mencapai hasil itu. (4) Orientasi orang: Sejauh mana keputusan manajemen memperhitungkan dampak hasil-hasil pada orang-orang di dalam organisasi itu. (5) Orientasi tim: sejauh mana kegiatan kerja diorganisasikan berdasarkan kelompok, bukannya berdasarkan individu. (6) Keagresifan: sejauh mana orang-orang itu agresif dan kompeten dan bukannya santai-santai. (7) Kemantapan: Sejauh mana kegiatan organisasi menekankan dipertahankannya status quo bukannya pertumbuhan. (Robbins, 2005)

Menurut McDonald mengatakan motivasi sebagai suatu perubahan tenaga di dalam diri seseorang yang ditandai oleh dorongan-dorongan afektif dan 
reaksi-reaksi dalam usaha mencapai tujuan. Dari pengertian yang dikemukakan Mc Donald ini mengandung tiga elemen penting yaitu: 1) Bahwa motivasi mengawali terjadinya perubahan energi pada diri setiap individu manusia. Perkembangan motivasi akan membawa beberapa perubahan energi di dalam system "neurophysiological" yang ada pada organism manusia. 2) Motivasi ditandai dengan munculnya rasa, afeksi seseorang. Dalam hal ini motivasi relevan dengan persoalan kejiwaan, afeksi dan emosi yang dapat menentukan tingkah laku manusia. 3) Motivasi ditandai oleh reaksi-reaksi mencapai tujuan. Jadi motivasi dalam hal ini sebenarnya merupakan respon dari suatu aksi, yakni tujuan. Motivasi memang muncul dari dalam diri manusia, tetapi kemunculannya karena dirangsang/didorong oleh adanya unsur lain dalam hal ini adalah tujuan. Tujuan ini akan menyangkut soal kebutuhan. (Sardiman, 2003)

$$
\text { Gray et.al, sebagaimana }
$$
diterjemahkan oleh mengemukakan 'motivasi merupakan hasil sejumlah proses, yang bersifat internal, atau eksternal bagi seorang individu yang menyebabkan timbulnya sikap entusiasme dan persistensi, dalam hal melaksanakan

kegiatan-kegiatan tertentu.' Oleh karena itu Jones 'menyatakan motivasi berhubungan dengan persoalan bagaimana perilaku diawali, dienergi, dipertahankan, diarahkan, dihentikan, dan jenis reaksi subyektif macam apa terdapat di dalam organisme yang bersangkutan, sewaktu segala hal yang dikemukakan berlangsung.' (Winardi, 2007)

Hamzah mengemukakan bahwa "Motivasi kerja adalah suatu proses yang dilakukan untuk menggerakan guru agar perilaku mereka dapat diarahkan pada upaya-upaya yang nyata untuk mencapai tujuan yang telah ditetapkan". Besar atau kecilnya pengaruh motivasi pada kinerja seseorang tergantung pada seberapa banyak intensitas motivasi yang diberikan. (Hamzah, 2007)

\section{METODE PENELITIAN}

Penelitian ini menggunakan pendekatan kuantitatif. Populasi dalam penelitian ini adalah seluruh guru SD Negeri pada Gugus Dewi Sartika di UPTD Pendidikan Kecamatan Sukra Kabupaten Indramayu yang berjumlah 35 orang. Dengan jumlah guru yang 35 orang tersebut, seluruhnya akan diteliti. Sehingga sampel dalam penelitian ini merupakan sampel jenuh karena seluruh populasi menjadi responden. 


\section{HASIL DAN PEMBAHASAN}

Untuk mengetahui besarnya pengaruh perilaku kepemimpinan kepala sekolah (X1) secara individual (parsial) terhadap motivasi kerja guru (Y) dapat dilihat dari nilai t pada tabel Coefficients dibawah ini dengan kriteria pengujian jika tingkat signifikansi lebih kecil dari 0,05, maka hipotesis diterima. Adapun hasil pengujian hipotesis tersebut adalah sebagai berikut tercantum pada tabel 1 .

Tabel 1

\section{Uji Hipotesis (t) Variabel $X_{1}$ terhadap $Y$}

\begin{tabular}{|c|c|c|c|c|c|}
\hline \multirow[b]{2}{*}{ Model } & \multicolumn{2}{|c|}{$\begin{array}{c}\text { Unstandardized } \\
\text { Coefficients } \\
\end{array}$} & \multirow{2}{*}{$\begin{array}{c}\text { Standardized } \\
\text { Coefficients } \\
\text { Beta }\end{array}$} & \multirow[b]{2}{*}{$\mathrm{t}$} & \multirow[b]{2}{*}{ Sig. } \\
\hline & $B$ & Std. Error & & & \\
\hline $1 \quad$ (Constant) & 61,355 & 8,754 & & 7,009 &, 000 \\
\hline $\begin{array}{l}\text { Perilaku_Kepemimpinan_Kep } \\
\text { ala Sekolah X1 }\end{array}$ & ,359 & ,098 & ,538 & 3,663 & ,001 \\
\hline
\end{tabular}

Berdasarkan tabel hasil uji $\mathrm{t}$ diperoleh bahwa nilai t hitung variabel perilaku kepemimpinan kepala sekolah (X1) memiliki nilai sebesar p-value $0,001<0,05 \quad$ artinya berdistribusi signifikan. Hal tersebut berarti perilaku kepemimpinan kepala sekolah (X1) secara parsial berpengaruh terhadap motivasi kerja guru (Y).

\section{Tabel 2}

Uji Anova

Pengaruh Perilaku Kepemimpinan Kepala Sekolah Terhadap Motivasi Kerja Guru

\begin{tabular}{|ll|r|r|r|r|r|}
\hline Model & & Sum of Squares & Df & Mean Square & \multicolumn{1}{|c|}{ F } & Sig. \\
\hline 1 & Regression & 484,273 & 1 & 484,273 & 13,414 & \multirow{2}{*}{$001^{\mathrm{b}}$} \\
& Residual & 1191,327 & 33 & 36,101 & & \\
& Total & 1675,600 & 34 & & & \\
\hline
\end{tabular}

Berdasarkan tabel 2 hasil uji anova atau F test didapat Fhitung sebesar 13,414 dan nilai signifikansi $0,001<0,05$. Dengan demikian Ho ditolak artinya pengaruh perilaku kepemimpinan kepala sekolah terhadap motivasi kerja guru SD
Negeri pada Gugus Dewi Sartika di UPTD Pendidikan Kecamatan Sukra Kabupaten Indramayu adalah signifikan. Untuk mengetahui besarnya pengaruh budaya organisasi (X2) secara individual (parsial) terhadap motivasi kerja guru (Y) 
dapat dilihat dari nilai $\mathrm{t}$ pada tabel Coefficients dibawah ini dengan kriteria pengujian jika tingkat signifikansi lebih kecil dari 0,05, maka hipotesis diterima. Adapun hasil pengujian hipotesis tersebut adalah sebagai berikut:

Tabel 3

\section{Uji Hipotesis ( $(t)$ Variabel $X_{2}$ terhadap $Y$}

\begin{tabular}{|c|c|c|c|c|c|}
\hline \multirow[b]{2}{*}{ Model } & \multicolumn{2}{|c|}{$\begin{array}{c}\text { Unstandardized } \\
\text { Coefficients }\end{array}$} & \multirow{2}{*}{$\begin{array}{c}\begin{array}{c}\text { Standardized } \\
\text { Coefficients }\end{array} \\
\text { Beta }\end{array}$} & \multirow[b]{2}{*}{$\mathrm{T}$} & \multirow[b]{2}{*}{ Sig. } \\
\hline & $\mathrm{B}$ & Std. Error & & & \\
\hline $1 \quad$ (Constant) & 41,127 & 12,072 & & 3,407 &, 002 \\
\hline Budaya_Organisasi_X2 &, 564 &, 130 & ,602 & 4,327 & ,000 \\
\hline
\end{tabular}

Berdasarkan tabel hasil uji $\mathrm{t}$ diperoleh bahwa nilai thitung variabel budaya organisasi (X2) memiliki nilai sebesar pvalue $0,000<0,05$ artinya signifikan.
Dengan demikian budaya organisasi (X2) secara parsial berpengaruh terhadap motivasi kerja guru (Y).

Tabel 4

Uji Anova

Pengaruh Budaya Organisasi Terhadap Motivasi Kerja Guru

\begin{tabular}{|rr|r|r|r|r|r|}
\hline Model & & Sum of Squares & df & Mean Square & \multicolumn{1}{c|}{$\mathrm{F}$} & Sig. \\
\hline 1 & Regression & 606,582 & 1 & 606,582 & 18,725 &, $000^{\mathrm{b}}$ \\
& Residual & 1069,018 & 33 & 32,394 & & \\
& Total & 1675,600 & 34 & & & \\
\hline
\end{tabular}

Berdasarkan tabel 4 hasil uji anova atau F test didapat Fhitung sebesar 18,725 dan signifikansi $0,000<0,05$ sehingga Ho ditolak artinya pengaruh budaya organisasi terhadap motivasi kerja guru SD Negeri pada Gugus Dewi Sartika di UPTD Pendidikan Kecamatan Sukra Kabupaten Indramayu adalah signifikan. Untuk mengetahui besarnya pengaruh perilaku kepemimpinan kepala sekolah
(X1) dan budaya organisasi secara bersama-sama (ganda) terhadap motivasi kerja guru (Y) dapat dilihat dari nilai $\mathrm{t}$ pada tabel Coefficients dibawah ini dengan kriteria pengujian jika tingkat signifikansi lebih kecil dari 0,05, maka hipotesis diterima. Adapun hasil pengujian hipotesis tersebut adalah sebagai berikut tercantum pada tabel 5 . 


\section{Tabel 5}

\section{Uji Hipotesis (t) Variabel $X_{1}$ dan $X_{2}$ terhadap $Y$}

\begin{tabular}{|c|c|c|c|c|c|c|}
\hline \multirow{2}{*}{\multicolumn{2}{|c|}{ Model }} & \multicolumn{2}{|c|}{$\begin{array}{c}\text { Unstandardized } \\
\text { Coefficients }\end{array}$} & \multirow{2}{*}{$\begin{array}{c}\text { Standardized } \\
\text { Coefficients } \\
\text { Beta }\end{array}$} & \multirow[b]{2}{*}{$\mathrm{t}$} & \multirow[b]{2}{*}{ Sig. } \\
\hline & & $\mathrm{B}$ & Std. Error & & & \\
\hline \multirow[t]{3}{*}{1} & (Constant) & 32,345 & 11,729 & & 2,758 & ,010 \\
\hline & $\begin{array}{l}\text { Perilaku_Kepemimpinan_Kepa } \\
\text { la_Sekolah_X1 }\end{array}$ & ,236 & ,094 & ,354 & 2,520 &, 017 \\
\hline & Budaya_Organisasi_X2 & ,432 & ,132 & ,461 & 3,277 & ,003 \\
\hline
\end{tabular}

Berdasarkan tabel 5 hasil uji t diperoleh bahwa nilai thitung variabel perilaku kepemimpinan kepala sekolah (X1) dan budaya organisasi (X2) secara bersamasama (simultan) memiliki nilai sebesar pvalue $0,000<0,05$ artinya signifikan.
Dengan demikian perilaku kepemimpinan kepala sekolah (X1) dan budaya organisasi (X2) secara bersama-sama (simultan) berpengaruh terhadap motivasi kerja guru (Y).

Tabel 6

Uji ANOVA

Pengaruh Perilaku Kepemimpinpinan Kepala Sekolah dan Budaya Organisasi Terhadap Motivasi Kerja Guru

\begin{tabular}{|ll|r|r|r|r|r|}
\hline Model & & Sum of Squares & Df & Mean Square & F & Sig. \\
\hline 1 & Regression & 783,553 & 2 & 391,777 & 14,054 &, $000^{\mathrm{b}}$ \\
& Residual & 892,047 & 32 & 27,876 & & \\
& Total & 1675,600 & 34 & & & \\
\hline
\end{tabular}

Berdasarkan tabel 6 hasil uji anova atau F test didapat Fhitung sebesar 14,054 dan signifikansi $0,000<0,05$ sehingga Ho ditolak artinya pengaruh perilaku kepemimpinan kepala sekolah dan budaya organisasi terhadap motivasi kerja guru.
Permasalahan yang ingin dijawab dalam penelitian ini pertama, adalah adakah pengaruh perilaku kepemimpinan kepala sekolah terhadap motivasi kerja guru SD Negeri pada Gugus Dewi Sartika di UPTD Pendidikan Kecamatan Sukra Kabupaten Indramayu. Secara empirik, hasil penelitian ini menginformasikan: 
(1) terdapat pengaruh positif dan signifikan antara perilaku kepemimpinan kepala sekolah terhadap motivasi kerja guru SD Negeri pada Gugus Dewi Sartika di UPTD Pendidikan Kecamatan Sukra Kabupaten Indramayu, serta (2) besarnya kontribusi terhadap motivasi kerja guru SD Negeri pada Gugus Dewi Sartika di UPTD Pendidikan Kecamatan Sukra Kabupaten Indramayu ditunjukkan oleh hasil penelitian bahwa perilaku kepemimpinan kepala sekolah yang terdiri dari dimensi: (1) perilaku yang timbul karena sesuatu sebab, (2) perilaku diarahkan pada tujuan, (3) Perilaku yang terarah kepada tujuan dapat diganggu oleh prestasi, konflik, dan kegelisahan, (4) perilaku timbul karena motivasi (Gibson, 2005). membawa implikasi yang signifikan terhadap motivasi kerja guru yang meliputi dimensi: (1) Dimensi internal atau motivasi intrinksik dan (2) Motivasi eksternal atau motivasi ekstrinksik (Gray et. al, 2000 dalam Winardi, 2007).

Namun demikian motivasi kerja guru SD Negeri pada Gugus Dewi Sartika di UPTD Pendidikan Kecamatan Sukra Kabupaten Indramayu ini tidak hanya dipengaruhi oleh perilaku kepemimpinan kepala sekolah saja, ada faktor lain (epsilon), selain dari budaya organisasi, yang juga berpengaruh, yang tidak dikaji dalam penelitian ini. Dengan demikian, hasil penelitian ini mengindikasikan bahwa semakin bagus perilaku kepemimpinan kepala SD Negeri pada gugus Dewi Sartika di UPTD Pendidikan Kecamatan Sukra Kabupaten Indramayu, maka akan diikuti oleh semakin tingginya motivasi kerja guru. Hal ini dapat diterangkan oleh persamaan regresi $\mathrm{y}=$ $61,355+0,359$. Dengan persamaan regresi tersebut dapat diinterpretasikan bahwa jika perilaku kepemimpinan kepala sekolah (X1) dengan motivasi kerja guru (Y) diukur dengan instrumen yang dikembangkan dalam penelitian ini, maka setiap perubahan skor perilaku kepemimpinan kepala sekolah sebesar satu satuan dapat diestimasikan skor motivasi kerja guru akan berubah 0,359 satuan pada arah yang sama.

Berdasarkan temuan empirik yang menunjukkan adanya pengaruh yang signifikan pengaruh kepamimpinan kepala sekolah dengan motivasi kerja guru, maka hasil penelitian ini memberikan beberapa informasi, di antaranya: (1) perilaku kepemimpinan kepala SD Negeri pada Gugus Dewi Sartika di UPTD Pendidikan Kecamatan Sukra Kabupaten Indramayu memberikan kontribusi yang berarti terhadap motivasi kerja guru, (2) salah satu cara untuk meningkatkan motivasi kerja guru SD 
Negeri pada Gugus Dewi Sartika di UPTD Pendidikan Kecamatan Sukra Kabupaten Indramayu adalah dengan meningkatkan perilaku kepemimpinan kepala sekolah, serta (3) persentase kontribusi perilaku kepemimpinan kepala sekolah terhadap motivasi kerja guru adalah sebesar $28,9 \%$, sementara sisanya sebesar $71,1 \%$ dipengaruhi oleh variabel lain, selain variabel budaya organisasi, yang tidak dikaji dalam penelitian ini (epsilon).

Kedua, adakah pengaruh budaya organisasi terhadap motivasi kerja guru SD Negeri pada Gugus Dewi Sartika di UPTD Pendidikan Kecamatan Sukra Kabupaten Indramayu. Secara empirik, hasil penelitian ini menginformasikan bahwa: (1) terdapat pengaruh positif dan signifikan antara budaya organisasi terhadap motivasi kerja guru SD Negeri pada Gugus Dewi Sartika di UPTD Pendidikan Kecamatan Sukra Kabupaten Indramayu, serta (2) besarnya kontribusi budaya organisasi terhadap motivasi kerja guru SD Negeri pada Gugus Dewi Sartika di UPTD Pendidikan Kecamatan Sukra Kabupaten Indramayu ditunjukkan oleh hasil penelitian bahwa budaya organisasi yang terdiri dari dimensi: (1) Kepercayaan, (2) Persepsi, (3) Norma, (4) Kekhasan, dan (5) Pola Perilaku (Gibson et.al., 2006), membawa implikasi yang signifikan terhadap motivasi kerja guru yang meliputi dimensi: (1) Dimensi internal atau motivasi intrinksik dan (2) Motivasi eksternal atau motivasi ekstrinksik (Gray et. al, 2000 dalam Winardi, 2007). Namun demikian motivasi kerja guru SD Negeri pada Gugus Dewi Sartika di UPTD Pendidikan Kecamatan Sukra Kabupaten Indramayu ini tidak hanya dipengaruhi oleh budaya organisasi saja, ada faktor lain (epsilon), selain dari perilaku kepemimpinan kepala sekolah, yang juga berpengaruh, yang tidak dikaji dalam penelitian ini.

Dengan demikian, hasil penelitian ini mengindikasikan bahwa semakin tinggi budaya organisasi pada SD Negeri Gugus Dewi Sartika di UPTD Pendidikan Kecamatan Sukra Kabupaten Indramayu, maka akan diikuti oleh semakin tingginya Motivasi kerja guru. Hal ini dapat diterangkan oleh persamaan regresi $\mathrm{y}=$ $41,127+0,564 X 2$. Dengan persamaan regresi tersebut dapat diinterpretasikan bahwa jika budaya organisasi (X2) dengan motivasi kerja guru (Y) diukur dengan instrumen yang dikembangkan dalam penelitian ini, maka setiap perubahan skor budaya organisasi sebesar satu satuan dapat diestimasikan skor motivasi kerja guru akan berubah 0,564 satuan pada arah yang sama. 
Berdasarkan temuan empirik yang menunjukkan adanya pengaruh yang signifikan budaya organisasi dengan motivasi kerja guru, maka hasil penelitian ini memberikan beberapa informasi, di antaranya: (1) budaya organisasi pada SD Negeri Gugus Dewi Sartika di UPTD Pendidikan Kecamatan Sukra Kabupaten Indramayu memberikan kontribusi yang berarti terhadap motivasi kerja guru, (2) salah satu cara untuk meningkatkan motivasi kerja guru SD Negeri pada Gugus Dewi Sratika di UPTD Pendidikan Kecamatan Sukra Kabupaten Indramayu adalah dengan meningkatkan budaya organisasi, serta (3) persentase kontribusi budaya organisasi terhadap motivasi kerja guru adalah sebesar 36,2\%, sementara sisanya sebesar $63,8 \%$ dipengaruhi oleh variabel lain, selain variabel perilaku kepemimpinan kepala sekolah, yang tidak dikaji dalam penelitian ini (epsilon).

Ketiga, pengaruh perilaku kepemimpinan kepala sekolah dan budaya organisasi terhadap motivasi kerja guru SD Negeri pada Gugus Dewi Sartika di UPTD Pendidikan Kecamatan Sukra Kabupaten Indramayu. Secara empirik, hasil penelitian ini menginformasikan: (1) terdapat pengaruh positif dan signifikan antara perilaku kepemimpinan kepala sekolah dan budaya organisasi secara bersama-sama terhadap motivasi kerja guru pada SD Negeri Gugus Dewi Sartika di UPTD Pendidikan Kecamatan Sukra Kabupaten Indramayu, serta (2) besarnya pengaruh perilaku kepemimpinan kepala sekolah dan budaya organisasi terhadap motivasi kerja guru SD Negeri pada Gugus Dewi Sartika di UPTD Pendidikan Kecamatan Sukra Kabupaten Indramayu ditunjukkan oleh hasil penelitian bahwa perilaku kepemimpinan kepala sekolah yang terdiri dari dimensi: (1) perilaku yang timbul karena sesuatu sebab, (2) perilaku diarahkan pada tujuan, (3) Perilaku yang terarah kepada tujuan dapat diganggu oleh prestasi, konflik, dan kegelisahan, (4) perilaku timbul karena motivasi (Gibson, 2005), serta budaya organisasi yang terdiri atas dimensi:

Kepercayaan, (2) Persepsi, (3) Norma, (4) Kekhasan, dan (5) Pola Perilaku (Gibson et.al., 2006), membawa implikasi yang signifikan terhadap motivasi kerja guru yang meliputi dimensi: (1) Dimensi internal atau motivasi intrinksik dan (2) Motivasi eksternal atau motivasi ekstrinksik (Gray et. al, 2000 dalam Winardi, 2007).

Namun demikian motivasi kerja guru SD Negeri pada Gugus Dewi Sartika di UPTD Pendidikan Kecamatan Sukra Kabupaten Indramayu ini tidak hanya 
dipengaruhi oleh perilaku kepemimpinan kepala sekolah, dan budaya organisasi saja, ada faktor lain (epsilon), yang juga berpengaruh, yang tidak dikaji dalam penelitian ini. Dengan demikian, hasil penelitian ini mengindikasikan bahwa semakin baik perilaku kepemimpinan kepala sekolah, dan semakin tinggi budaya organisasi pada SD Negeri Gugus Dewi Sartika di UPTD Pendidikan Kecamatan Sukra Kabupaten Indramayu. Berdasarkan temuan empirik yang menunjukkan adanya pengaruh yang signifikan perilaku kepemimpinan kepala sekolah, dan budaya organisasi terhadap motivasi kerja guru, maka hasil penelitian ini memberikan beberapa informasi, di antaranya: (1) perilaku kepemimpinan kepala sekolah, dan budaya organisasi pada SD Negeri Gugus Dewi Sartika di UPTD Pendidikan Kecamatan Sukra Kabupaten Indramayu memberikan kontribusi yang berarti terhadap motivasi kerja guru, (2) salah satu cara untuk meningkatkan motivasi kerja guru SD Negeri pada Gugus Dewi Sartika di UPTD Pendidikan Kecamatan Sukra Kabupaten Indramayu adalah dengan meningkatkan perilaku kepemimpinan kepala sekolah dan budaya organisasi. (3) persentase kontribusi yang diberikan oleh perilaku kepemimpinan kepala sekolah dan budaya organisasi secara bersama- sama terhadap motivasi kerja guru adalah sebesar $46,8 \%$, sementara sisanya sebesar $53,2 \%$ dipengaruhi oleh variabel lain, yang tidak dikaji dalam penelitian ini (epsilon).

\section{PENUTUP}

Dari hasil penelitian dan pembahasan pad peneiltian ini, dapat disimpulkan:

Terdapat pengaruh yang signifikan antara perilaku kepemimpinan kepala sekolah terhadap motivasi kerja guru SD Negeri pada Gugus Dewi Sartika di UPTD Pendidikan Kecamatan Sukra Kabupaten Indramayu sebesar 28,9\%, sementara sisanya sebesar $71,1 \%$ dipengaruhi oleh variabel lain, selain variabel budaya organisasi, yang tidak dikaji dalam penelitian ini (epsilon).

2) Terdapat pengaruh yang signifikan antara budaya organisasi terhadap motivasi kerja guru SD Negeri pada Gugus Dewi Sartika di UPTD Pendidikan Kecamatan Sukra Kabupaten Indramayu sebesar 36,2\%, sementara sisanya sebesar $63,8 \%$ dipengaruhi oleh variabel lain, selain variabel perilaku kepemimpinan kepala sekolah, yang tidak dikaji dalam penelitian ini (epsilon).

3) Terdapat pengaruh yang signifikan antara perilaku kepemimpinan kepala sekolah dan budaya organisasi secara bersama-sama terhadap motivasi 
kerja guru SD Negeri pada Gugus Dewi

Sartika di UPTD Pendidikan Kecamatan

Sukra Kabupaten Indramayu sebesar $46,8 \%$, sementara sisanya sebesar 53,2\% dipengaruhi oleh variabel lain, yang tidak dikaji dalam penelitian ini (epsilon).

\section{UCAPAN TERIMAKASIH}

Terimkasih kepada semua pihak yang telah membantu penulisan karya ilmiah ini.

\section{DAFTAR PUSTAKA}

Danim, Sudarwan. (2007). Motivasi Kepemimpinan dan Efektifitas Kelompok. Jakarta: PT. AsdiMahayasa.

Depdiknas R.I. (2005). Kamus Besar Bahasa Indonesia. Jakarta: Balai Pustaka.

Fatah Nanang. (2006). Landasan Manajemen Pendidikan. Bandung: PT Remaja Rosdakarya Offset.

Gibson, James L., John M. Ivancevich dan James H. Donnelly, Jr. (2005). Organisasi, Perilaku, Struktur, Proses, (Alih Bahasa Nunuk Adiarni). Jakarta: Binarupa Aksara.

Gibson, et.al. (2006). Organisasi (Terjemahan). Edisi Ke-Lima. Jakarta: Erlangga.

Luthans, Fred. (2006). Perilaku Organisasi (edisi kesepuluh). Yogyakarta. Andi. (Versi Bahasa Indonesia)
Mondy, R., Wayne, Sharplin, Arthur, and Premeux, R. Shane. (2005). Management, Concepts, Practices, and Skills (Fifth ed). Massachusetts. Silmon \& Schuster, Inc.

Razik, Taher dan Swanson, Austin D. (2005). Konsep-konsep Fundamental dalam Kepemimpinan Pendidikan dan Manajemen. Prentice Hall.

Rivai, Veithzal. (2005). Kepemimpinan dan Perilaku Organisasi. Jakarta: PT Raja Grafindo Persada.

Robbins, Stephen P. (2005). Organizational Behavior (10th Edition). New Jersey. Prentice Hall, Inc. Indeks. (Versi Bahasa Indonesia)

Sardiman AM, (2003), Interaksi dan Motivasi Belajar Mengajar, Raja Grafindo Persada, Jakarta.

Thoha, Miftah. (2005). Perilaku Organisasi Konsep Dasar dan Aplikasi. Jakarta: PT Raja Grafindo Persada.

Undang-Undang RI No 14 Tahun 2005. Tentang Guru dan Dosen. Jakarta: Sinar Grafik.

Undang-Undang RI No 20 Tahun 2005. Tentang Sistem Pendidikan Nasional. Jakarta: Restindo Media Tama.

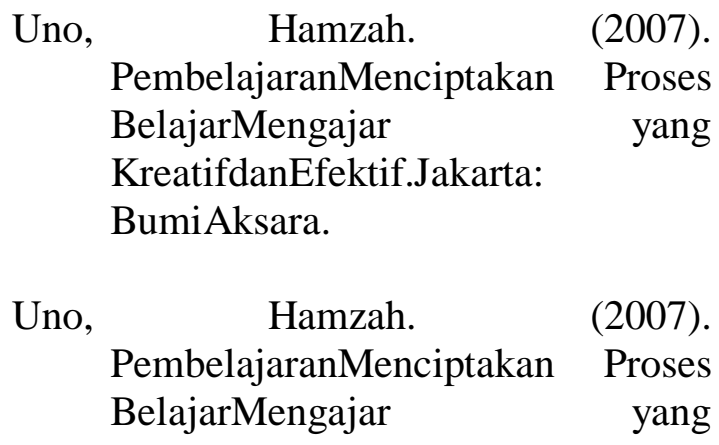


KreatifdanEfektif.Jakarta:

BumiAksara.

Wahab, Abdul Azis. (2007). Anatomi

Organisasi dan Kepemimpinan

Pendidikan. Bandung: Alfabeta.

Winardi (2007), Motivasi:Pemotivasian

Dalam Manajemen. Jakarta: PT. Raja

Grafindo Persada 